\title{
As consequências não-intencionais da instalação da Faculdade de Ciências Aplicadas da Unicamp em Limeira/SP - Uma perspectiva intersetorial.
}

\author{
Murilo Santos da Silva* (FCA/UNICAMP), Prof. Dr. Álvaro de Oliveira D'Antona (FCA/UNICAMP)
}

\section{Resumo}

O objetivo deste trabalho foi analisar a instalação da Faculdade de Ciências Aplicadas da Unicamp em Limeira/SP, pela ótica da urbanização, a fim de verificar de que forma sua instalação modificou a região do seu entorno imediato. Para a coleta de dados foram analisadas imagens aéreas, pesquisas bibliográficas, entrevistas com a população residente no entorno da Faculdade e com autoridades-chave no processo de instalação. Os resultados apontam para um descompasso entre o que o projeto poderia trazer de benefícios e o que de fato se concretizou no que tange às políticas públicas para a população do entorno. Isso deve-se ao modelo de governança utilizado pelos atores, os quais possuíam interesses, pressões e motivações diferentes. Com base nos resultados, verifica-se a necessidade da incorporação de novos arranjos institucionais e ações intersetoriais entre os atores, para que as oportunidades geradas pela urbanização da região, não venham a causar consequências não-intencionais intra e extramuros.

\section{Palavras-chave: Políticas Públicas, Intersetorialidade, Urbanização.}

\section{Introdução}

Este trabalho teve o intuito de analisar a instalação da Faculdade de Ciências Aplicadas da Unicamp em Limeira/SP. Seu objetivo específico foi verificar como a urbanização da região modificou o entorno e a mancha urbana próxima da FCA/UNICAMP.

O conceito de urbanização é polissêmico, mas para o recorte desta pesquisa entendemos urbanização como toda a infraestrutura e os serviços públicos necessários para uma determinada localidade urbana, como por exemplo: abastecimento de água, saneamento, eletricidade, asfaltamento assim como transporte coletivo, educação, saúde, coleta de lixo, segurança pública, habitação, entre outras.

Esta pesquisa obteve aprovação do Comitê de Ética em Pesquisa da Unicamp (CEP/UNICAMP), em 30/05/2016, com CAAE $\mathrm{N}^{\circ}$ 55942416.2.0000.5404. A intenção foi aprofundar os resultados obtidos no projeto de pesquisa de Silva (2016), "Impactos da instalação da Faculdade de Ciências Aplicadas da UNICAMP, em Limeira/SP percepção da população do entorno." (PIBIC-SAE/UNICAMP-2015-16)

$\mathrm{Na}$ referida pesquisa, identificou-se que na percepção da população do entorno, dentre as consequências não-intencionais ${ }^{1}$ da instalação da Faculdade de Ciências Aplicadas da Unicamp em Limeira ${ }^{2}$, dois itens se destacaram: (1) o aumento do valor dos aluguéis para os estudantes, e (2) o aumento da criminalidade (furtos e roubos) também para com os estudantes. Diante dos resultados obtidos, verificou-se a necessidade de aprofundar a discussão em torno das consequências não-intencionais resultantes da instalação da FCA e analisar a partir de uma perspectiva intersetorial o papel integrado das políticas públicas que permitem o funcionamento da Faculdade de Ciências Aplicadas da Unicamp, construída no campus Cidade Universitária de Limeira.

\section{Resultados e Discussão}

De acordo com a pesquisa realizada por Silva (2016), com 21 moradores residentes no entorno da Faculdade de Ciências Aplicadas da Unicamp, estes foram questionados sobre as mudanças ocorridas em seus bairros nos últimos anos, e os resultados foram os seguintes:

Figura 01. Mudanças no entorno (Jardim Morro Azul e Jardim Paulista) Quais mudanças ocorreram no bairro nos últimos anos?

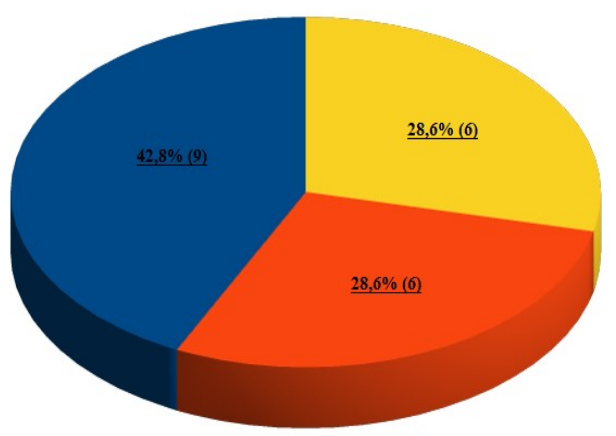

- A construção da FCA/UNICAMP

Mudanças estruturais (instalação de comércios, de transporte público) Nada mudou no bairro

Fonte: Elaborado por Silva (2016)

Baseado nos dados da figura 01, verifica-se que a instalação da FCA/UNICAMP representou para a maioria dos entrevistados uma das principais mudanças no entorno. Quanto às mudanças estruturais, boa parte destas fizeram parte do processo de adequação e urbanização da região para receber o novo campus da UNICAMP.

A seguir serão apresentadas e analisadas parte destas mudanças por meio de dois mapas da região em diferentes períodos, antes da construção da FCA e atualmente.

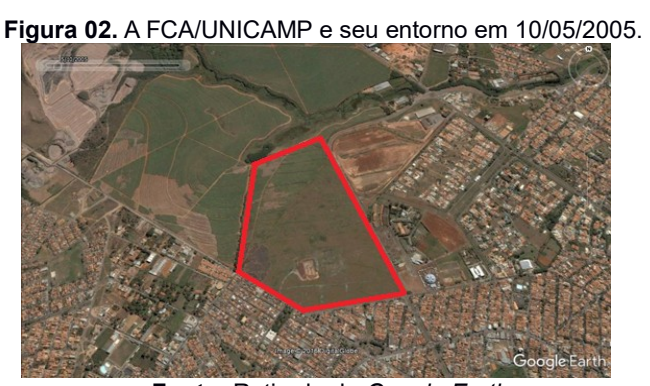

Fonte: Retirado do Google Earth

Na figura 02, ainda não havia nada construído no terreno do campus (área destacada em vermelho) que hoje abriga a FCA/UNICAMP.

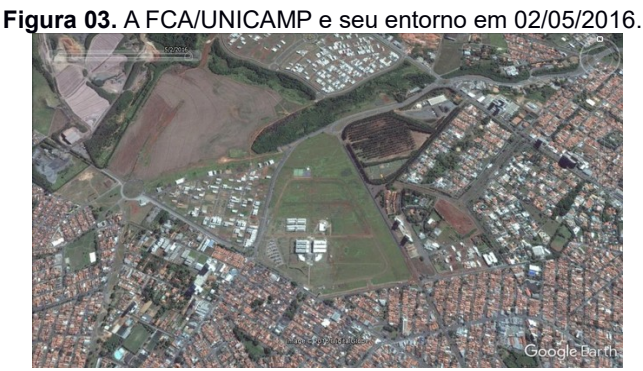

Fonte: Retirado do Google Earth

A figura 03, representa o momento atual da região da FCA/UNICAMP, o sistema viário encontra-se em obras, mas ainda não foi entregue completamente conforme prometido pela municipalidade. $\mathrm{O}$ setor imobiliário avança, porém já não com a mesma força e intensidade dos primeiros anos. No interior do campus também não existem grandes obras em andamento.

\section{Conclusões}

A FCA/UNICAMP modificou o seu entorno, tanto pela ótica da urbanização, que foi a principal e primeira mudança verificada após a instalação da unidade, quanto pela necessidade de uma rede integrada de políticas públicas que atendesse o campus e o seu entorno, fato este que ainda não aconteceu de maneira efetiva.

Incorporar medidas como a intersetorialidade, a governança em políticas públicas e novos arranjos institucionais entre os atores e interessados talvez fosse uma das saídas para que a instalação da FCA/UNICAMP pudesse trazer ganhos ainda maiores e beneficiar a todos os contribuintes, intra e extramuros, oferecendo-lhes as benesses do investimento púbico e não as consequências não-intencionais, como o aumento no valor dos aluguéis e da criminalidade, além da visão de alguns moradores de que ao enxergar a Universidade, veem apenas prédios, ou seja, acabam não enxergando uma instituição pública, pois a urbanização abriu os "caminhos", mas as políticas públicas ainda não chegaram.

Agradecimentos
Agradeço ao CNPq e ao SAE/UNICAMP pelo financiamento
desta pesquisa.


atores. II ENPP, Araraquara, junho/2016. p. 1930-1971. Disponível em https:/goo.gl/3paVXA Acesso em 20/10/201థDOI: 10.19146/pibic-2017-78464 